\title{
Rede Social de Aprendizagem Colaborativa para Surdos e Deficientes Auditivos
}

\author{
Isabella Sakis - PPGTER/UFSM - isabellasakis@gmail.com \\ Giliane Bernardi - PPGTER/UFSM - giliane@inf.ufsm.br
}

\begin{abstract}
Resumo. A inclusão educacional de surdos e deficientes auditivos no ensino superior pode ser promovida com a oferta de materiais didáticos acessíveis, pois, se estes forem apenas em Língua Portuguesa, poderão não ser compreendidos pelos que não dominam essa língua. Considerando-se o papel das tecnologias e das redes sociais na inclusão social desses alunos, acredita-se que estas podem ser utilizadas também para promover a sua inclusão educacional. Assim, dentro desta perspectiva, foi desenvolvida uma rede social de aprendizagem colaborativa, em que usuários surdos ou deficientes auditivos podem compartilhar materiais didáticos acessíveis. Esse artigo relata a modelagem, o desenvolvimento e as avaliações iniciais dessa aplicação, que segue em contínuo desenvolvimento para aprimorar suas funcionalidades e torná-la cada vez mais adequada às necessidades dos usuários.
\end{abstract}

Palavras-chave: Rede social; Aprendizagem Colaborativa; Surdos; Deficientes auditivos; Acessibilidade.

\section{Social Collaborative Learning Network For The Deaf and Hearing Impaired}

\begin{abstract}
The educational inclusion of deaf and hearing impaired in higher education can be promoted with the offer of accessible teaching materials, because, if they are only in portuguese, they may not be understood by students who do not master this language. Considering the function of technologies and social networks in the social inclusion of this students, it is believed that these can be used also to promote your educational inclusion. Thus, inside of these perspective, was developed a social collaborative learning network, in which users who are deaf and hearing impaired can share accessible teaching materials. This paper reports the modeling, develop and initial evaluations of this application, which is in continuous development, to improve its functionalities and make it more and more suited to the user's needs.
\end{abstract}

Keywords: Social network; Collaborative Learning; Deaf; Hearing impaired; Accessibility.

\section{Introdução}

A compreensão das necessidades envolvidas na educação dos surdos, exige, primeiramente, o conhecimento acerca da identidade e cultura surdas. A identidade dos surdos é concebida a partir das suas características culturais, que dizem respeito à como eles se relacionam, aprendem e se constituem, sendo que a sua principal característica é a forma visual com que eles recebem informações e se expressam: a Língua de Sinais (Gomes, 2015). Para Gesser (2009), "o surdo desenvolve suas habilidades cognitivas e linguísticas ao lhe ser assegurado o uso da Língua de Sinais em todos os âmbitos sociais em que transita". Essa perspectiva não deve ser ignorada no âmbito educacional, principalmente em Instituições de Ensino Superior (IES), nas quais, apesar do crescente número de matrículas, as taxas de conclusão mantém-se baixas, conforme dados divulgados no Censo de Educação Superior anualmente (MEC/INEP, 2019).

Apesar da presença de intérpretes durante as aulas ser garantida pela legislação no Brasil, o domínio da Língua Portuguesa como segunda língua escrita ainda é necessário para compressão dos materiais didáticos e trabalhos que devem ser 
acessados/realizados fora do espaço de sala de aula. No entanto, caso o processo de aprendizagem desta língua não tenha ocorrido por meio da Língua Brasileira de Sinais (Libras) como língua de instrução, esses alunos podem chegar ao ensino superior sem este domínio (Quadros; Souza, 2013). Ao considerar isso, percebe-se que as barreiras na educação dos surdos não são somente comunicacionais, mas também pedagógicas, pois eles podem não compreender os materiais didáticos oferecidos em aula.

As Tecnologias Digitais (TD) e as redes sociais têm desempenhado um importante papel na comunicação e interação entre os surdos. Desde os tempos do Orkut, os surdos já utilizavam as redes sociais, buscando, principalmente, manter relações de amizades com outros surdos (Barbosa, 2012). Para Ramos (2014), as interações entre os surdos nas redes sociais reforçam as identidades surdas, possibilitando o diálogo e a troca de informações em redes virtuais. Em um contexto mais atual, os participantes da pesquisa de Morais (2018) sobre o uso de redes sociais e aplicativos de interação por surdos, relataram utilizar, em sua maiora, o Facebook, o Instagram, o Twitter, e o Youtube, em busca de colocação profissional (emprego), estabelecer comunicação com os familiares e amigos (surdos ou ouvintes) e para ter acesso à informações e notícias. Apesar dos autores concordarem sobre a importância das redes sociais na inclusão social dos surdos, eles afirmam que existem limitações, tanto na acessibilidade, quanto na promoção da inclusão educacional, que exige mais do que se oferece em redes sociais tradicionais, pois "é preciso compreender o verdadeiro sentido da inclusão" (Morais, 2018).

Nesse contexto, considerando-se que as TD podem potencializar os processos educacionais (Tajra, 2019), as redes sociais podem proporcionar não só uma melhor comunicação entre os surdos, mas também auxiliar na sua inclusão educacional, por meio da oferta de materiais didáticos acessíveis. Com este objetivo, realizou-se o desenvolvimento de uma rede social de aprendizagem colaborativa, na qual é possível compartilhar materiais didáticos acessíveis a surdos e deficientes auditivos, processo relatado neste artigo. O artigo apresenta a seguinte estrutura: na seção 2 são relatados os trabalhos relacionados, na seção 3 é detalhada a metodologia empregada, na seção 4 são expostos e discutidos os resultados obtidos até o estágio atual de desenvolvimento e, por fim, na seção 5, constam as considerações finais.

\section{Trabalhos Relacionados}

No levantamento dos trabalhos relacionados considerou-se dois vieses: o acadêmico e o comercial. Para o viés acadêmico, analisou-se os resultados de uma Revisão Sistemática de Literatura (RSL) realizada na fase de levantamento bibliográfico, e publicada em Sakis et al. (2018), que investigou tecnologias que podem auxiliar na inclusão educacional de surdos ou deficientes auditivos. Foram analisados 57 estudos, publicados entre 2007 e 2017, nos principais periódicos e anais de eventos de Informática na Educação do Brasil, que relataram o uso e/ou desenvolvimento de diversas tecnologias, principalmente jogos, AVAs e arquiteturas pedagógicas, cujo propósito, em sua maioria, era de apoiar o ensino de Libras e Língua Portuguesa.

Entre os estudos encontrados, três relatam a oferta de materiais didáticos acessíveis para surdos em ambientes digitais. Lapolli et al. (2014) desenvolveram um material didático acessível no formato de infografia na web, sobre Geometria Descritiva e projeção cilíndrica ortogonal. O trabalho de (Gonçalves et al., 2015) relatou a oferta de cursos EAD de programação em Java, através de videoaulas acessíveis disponibilizadas em um AVA. Sarmento e Rego (2017) também disponibilizaram em uma arquitetura pedagógica videoaulas acessíveis para um curso especializante.

V. $18 \mathrm{~N}^{\mathrm{o}} 1$, julho, 2020

RENOTE DOI: 
No viés comercial foram encontradas, com buscas manuais, quatro redes sociais de aprendizagem colaborativa: duas brasileiras - Passei direto e Trabalhos feitos ${ }^{2}$; e

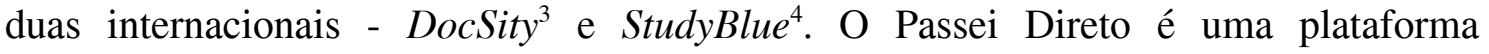
gamificada que oferece aos usuários materiais didáticos de acordo com a sua faculdade, curso e disciplinas. Já, a plataforma Trabalhos Feitos, permite a distribuição de variados tipos de trabalhos acadêmicos. A DocSity e o StudyBlue são direcionadas aos ensinos médio e superior e permitem o compartilhamento de materiais de estudo online, sendo que a StudyBlue ainda permite a criação de Flash Cards, para disponibilizar fichas de estudos e questionários. Alguns recursos dessas ferramentas possuem semelhança com a aplicação apresentada neste artigo, como o compartilhamento de materiais didáticos e a sua divisão em áreas de ensino. Outras funcionalidades, como a gamificação e a produção de Flash Cards, serão consideradas futuramente.

No que tange as redes sociais direcionadas à comunidade surda, foram encontrados relatos da existência de duas que tiveram seu desenvolvimento descontinuado, a Prodeaf e Deafpals. Além disso, foram encontrados dois fóruns internacionais para comunicação entre surdos: o Alldeaf $f^{5}$ - fórum público para surdos e deficientes auditivos mais popular do mundo; e o fórum "We cannot hear"6, disponível no Reddit, que apresentam semelhanças em relação às interações de redes sociais tradicionais. As estratégias de interação desses fóruns serão analisadas mais profundamente, para talvez serem empregados em futuros aprimoramentos.

Percebe-se, a partir desses relatos, que não foram encontradas outras redes sociais de aprendizagem direcionadas à comunidade surda, somente redes tradicionais e redes de aprendizagem sem foco em usuários surdos, e fóruns de comunicação para surdos. Considera-se, então, a rede social relatada neste artigo pertinente e necessária. A seguir, são relatados os processos metodológicos envolvidos no seu desenvolvimento.

\section{Metodologia}

Os métodos de pesquisa empregados neste trabalho podem ser caracterizados como exploratório, quanto aos objetivos, e como desenvolvimento experimental, quanto à finalidade, pois foi necessário levantamento bibliográfico para explicitar o problema e auxiliar no desenvolvimento de um produto (Gil, 2018). No levantamento bibliográfico, foram empregados os procedimentos de Pesquisa Bibliográfica (Gil, 2018) e Revisão Sistemática de Literatura (Kitchenham; Charters, 2007) e as avaliações foram guiadas pelo framework DECIDE (Preece et al., 2013), sendo que uma delas utilizou o método de Avaliação Heurística (Nielsen 1994).

A modelagem, implementação e avaliação da aplicação seguiu o Modelo de Ciclo de Vida Simples de Design de Interação Humano-Computador (IHC), que indica a criação de designs alternativos, que são avaliados para verificar se são necessárias modificações ou se o produto final pode ser finalmente gerado (Preece et al., 2013). A seguir, são descritas cada uma dessas fases.

- Identificação das necessidades e estabelecimento de requisitos: em um projeto de design de interação, é fundamental reconhecer as necessidades dos usuários para esclarecer o que espera-se do produto final. Diferentemente dos modelos de

\footnotetext{
${ }^{1}$ https://www.passeidireto.com/

${ }^{2}$ https://www.trabalhosfeitos.com/

${ }^{3}$ https://www.docsity.com/pt

${ }^{4}$ https://www.studyblue.com/

${ }^{5} \mathrm{http} / / / \mathrm{www}$.alldeaf.com/

${ }^{6} \mathrm{https}: / / \mathrm{www}$. reddit.com/r/deaf/

V. $18 \mathrm{~N}^{\mathrm{o}} 1$, julho, 2020
}

DOI: 
Engenharia de Software, em que são elencados requisitos funcionais e não-funcionais, no design de interação são necessários uma variedade de requisitos para uma modelagem mais completa: requisitos funcionais; de dados; ambientais; de usuário e de usabilidade (Preece et al., 2013).

- Design: o design desta aplicação foi desenvolvido sob o ponto de vista de dois aspectos: o de software e o de interação. O design de software foi modelado através dos Diagramas de Casos de Uso e de Classes, confeccionados utilizando a Unified Modeling Language (UML) ${ }^{7}$. Já o design de interação, foi modelado a partir da confecção dos protótipos das interfaces, através da ferramenta de prototipação Balsamiq ${ }^{8}$. Esses processos foram orientados pelo Modelo de Acessibilidade em Governo Eletrônico (eMAG) (Brasil, 2014), pelas Web Content Accessibility Guidelines (WCAG) (W3C, 2018) e pela especificação técnica WAI-ARIA (W3C, 2017). Os protótipos produzidos podem ser consultados em: https://bit.ly/3fuTrB9.

- Construção da versão interativa: as aplicações Web com as quais nos deparamos atualmente apresentam cada vez mais recursos tecnológicos avançados, que promovem primorosas interações do usuário com os elementos presentes nas páginas. Assim, na implementação da versão interativa desta aplicação, foram consideradas as tendências mundiais de desenvolvimento Web, que apontam para a utilização da linguagem de programação JavaScript ${ }^{9}$, juntamente com a utilização de bibliotecas e frameworks que possibilitam o desenvolvimento de aplicações Web avançadas e permitem uma experiência completa ao usuário.

- Avaliação: para garantir que as necessidades dos usuários sejam satisfeitas, é imprescindível a realização de avaliações durante e após o desenvolvimento. Assim, buscando antecipar possíveis problemas durante o processo, realizou-se uma Avaliação Heurística de Usabilidade e Acessibilidade, através da inspeção dos protótipos das interfaces por duas especialistas em IHC e uma especialista no ensino de Libras, para avaliar sob o aspecto da interação dos usuários surdos, com base nas Heurísticas de Usabilidade de Nielsen (Nielsen 1994) e em um conjunto de heurísticas concebido como um método alternativo de avaliação de acessibilidade (Tanaka 2009). Após a implementação da versão interativa, novas avaliações foram realizadas: uma manual, com o preenchimento do Checklist de Acessibilidade para o Desenvolvedor do Departamento de Governo Eletrônico (Brasil, 2010); e uma automática, realizada com a extensão do Google Chrome Visual ARIA ${ }^{10}$, que viabilizou a varredura do código local para validar quanto às regras da WAI-ARIA, já que o website ainda não foi publicado em um servidor. Os resultados das avaliações são apresentadas na próxima seção.

\section{Resultados e Discussão}

A seguir são relatados os resultados dos processos de desenvolvimento e avaliações da aplicação.

\subsection{Resultados Avaliação Heurística de Usabilidade e Acessibilidade}

Os resultados da avaliação heurística foram publicados em Sakis et al. (2020), sendo que, em síntese, foram encontradas 17 violações, 16 referentes às heurísticas de usabilidade e somente uma associada à acessibilidade. Quanto à gravidade dos problemas, 4 foram considerados problemas cosméticos, 9 pequenos e somente 4

\footnotetext{
${ }^{7}$ https://www.uml.org/

${ }^{8} \mathrm{https}: / /$ balsamiq.cloud

${ }^{9}$ https://www.javascript.com/

${ }^{10} \mathrm{https}: / /$ chrome.google.com/webstore/detail/visual-aria/lhbmajchkkmakajkjenkchhnhbadmhmk V. $18 \mathrm{~N}^{\mathrm{o}} 1$, julho, 2020 DOI: 
grandes. Ressalta-se que a maioria dos problemas diz respeito à percepção dos usuários com surdez ou deficiência auditiva, que pode ser distinta da percepção de outros usuários. Assim, alguns detalhes que provavelmente não seriam considerados como problemas de usabilidade para usuários ouvintes, foram apontados nesta avaliação. A partir desses resultados, percebeu-se que os protótipos da aplicação apresentavam um bom grau de conformidade com as heurísticas consideradas, pois a maioria dos problemas foram classificados como pequenos ou cosméticos e as sugestões de correções não exigem implementações complexas. Considera-se, então, que a realização desta avaliação mostrou-se pertinente e relevante, pois seus resultados serviram como base para o redesign da aplicação.

\subsection{Resultados da construção da versão interativa}

O desenvolvimento da versão interativa da aplicação foi orientado pelos padrões de acessibilidade já citados, mas também foram incluídos recursos extras de acessibilidade: o tradutor automático VLibras ${ }^{11}$ e vídeos manuais com a tradução de alguns conteúdos textuais para Libras. Até o presente momento, nem todas funcionalidades propostas foram desenvolvidas, e algumas passaram por modificações, devido ao redesign realizado após a avaliação heurística. As funcionalidades implementadas são relatadas a seguir, representadas através de alguns screenshots da aplicação, mas é possível visualizar os screenshots de todas páginas em: https://bit.ly/3h3fL5o. Todos os nomes de usuários e IES presentes são fictícios.

Ao realizar o login na plataforma, o usuário irá se deparar com uma interface semelhante ao Facebook, mas que inclui os elementos padronizados de acessibilidade em conformidade com as WCAG e as recomendações do eMAG. No cadastro do perfil, o usuário pode inserir, além dos seus dados básicos, a IES e o curso em que está matriculado e deve informar uma área de ensino de seu interesse, e seu objetivo no uso da plataforma (troca de conhecimentos, comunicação diária ou termos técnicos).

Na página inicial (Figura 01) estão dispostos os materiais compartilhados pelos usuários. O botão "Nova postagem" abre uma nova janela (Figura 02) para que o usuário possa inserir um material, que pode ser um arquivo, um vídeo ou uma imagem, e deve estar relacionado a uma área de ensino e a um objetivo, possibilitando que seja criada, assim, uma rede de relacionamentos entre as áreas de ensino e objetivos dos materiais e dos perfis dos usuários. Os usuários podem interagir nas postagens, através das reações de curtir, comentar, favoritar o material para a sua biblioteca e denunciar materiais que não considerarem acessíveis. A página do perfil de um usuário (Figura 03) contém as informações do usuário, o botão que redireciona para edição de perfil, o botão de nova postagem e as postagens do usuário. O link de uma área de ensino ou objetivo, presentes nas postagens e nos perfis dos usuários, redireciona à uma página com todas as postagens relacionadas ao objetivo ou à área de ensino.

Alguns dos itens necessários em websites acessíveis, que estão presentes nas interfaces, são: noção de localização, com breadcrumbs que indicam o caminho percorrido até chegar à página atual; barras de progresso para indicar carregamentos; mensagens de confirmação antes de finalizar uma ação que modifica dados na aplicação; e mensagens de feedback para informar execuções de ações.

Além disso, na barra de acessibilidade são oferecidos elementos de acessibilidade indicados pelo eMAG: atalhos rápidos, página sobre os elementos de acessibilidade do website, mapa do website e mudança de contraste. Nessa barra há

${ }^{11} \mathrm{http}: / / \mathrm{www} . v$ libras.gov.br/

V. $18 \mathrm{~N}^{\mathrm{o}} 1$, julho, 2020

RENOTE

DOI: 
também a indicação de que o VLibras pode ser utilizado para interpretar conteúdos textuais para Libras. Para complementar essa funcionalidade, foi adicionado, ao lado dos principais elementos, o ícone com o signo referente a sistemas acessíveis a surdos, que abre uma janela com um vídeo com a interpretação daquele conteúdo para Libras.

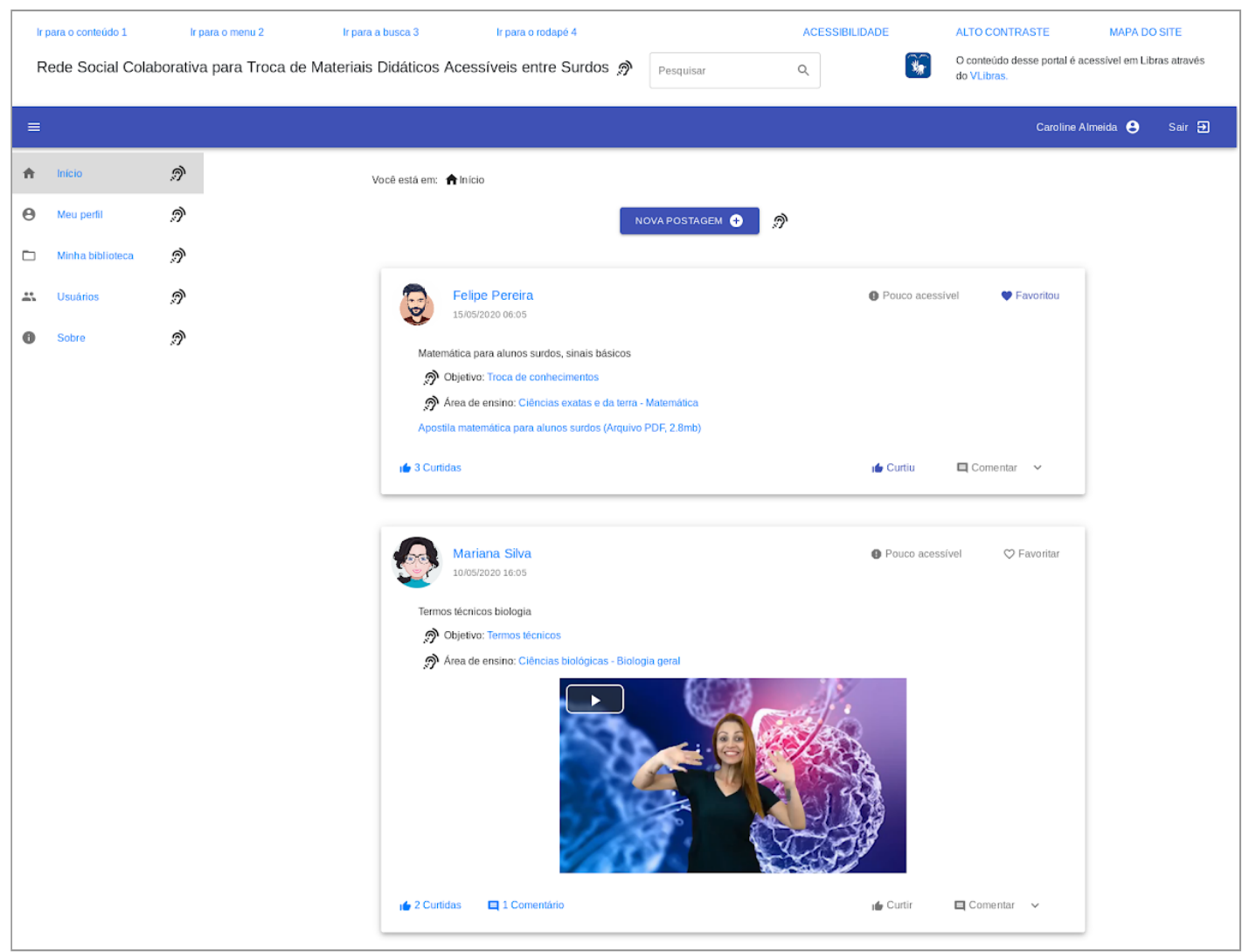

Figura 01 - Página Inicial da Rede Social.

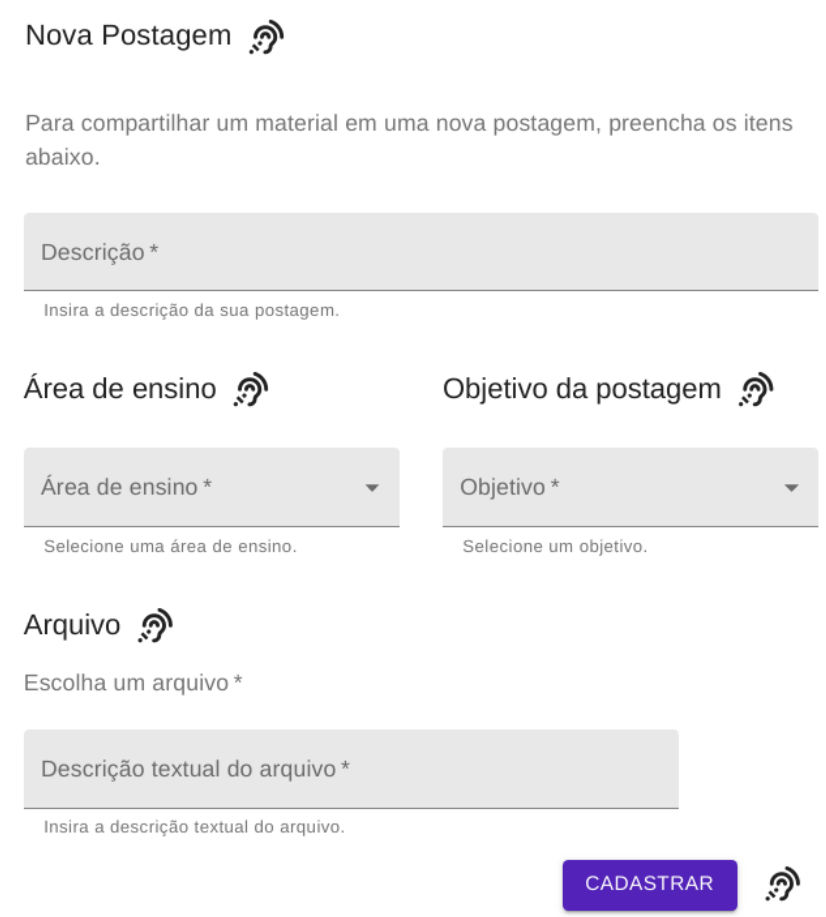

Figura 02 - Janela para cadastro de Nova Postagem.

V. $18 \mathrm{~N}^{\mathrm{o}} 1$, julho, 2020

DOI: 


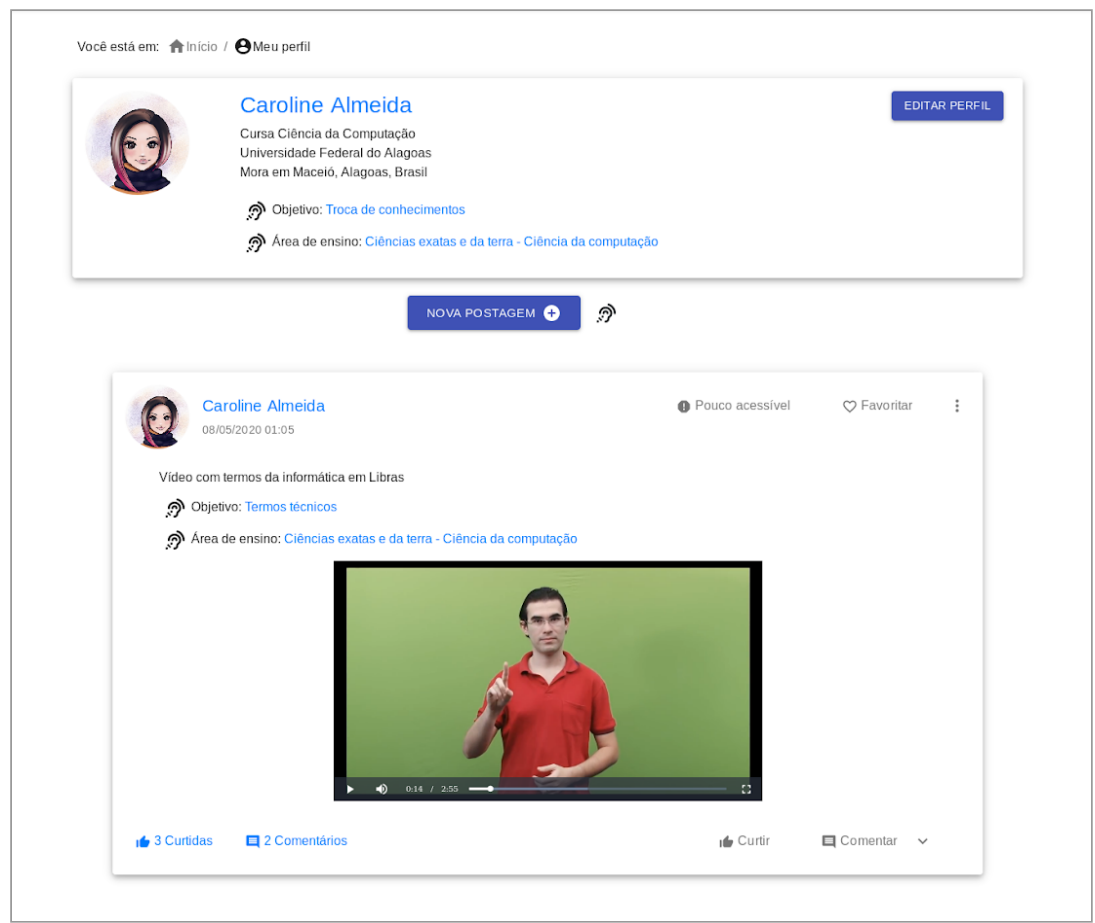

Figura 03 - Página do Perfil do Usuário.

\subsection{Resultados das avaliações da versão interativa}

As avaliações da versão interativa da aplicação envolveu uma avaliação automática, para examinar a conformidade com a WAI-ARIA, e uma manual, para verificar a conformidade com o eMAG. Esta foi realizada preenchendo o Checklist de Acessibilidade - Manual para o Desenvolvedor (Brasil, 2010), que também serviu como documento norteador durante o desenvolvimento. Os resultados dessa avaliação podem ser vistos na Tabela 1, onde são expostas as respostas para cada item do Checklist.

Tabela 1 - Resultados avaliação manual.

\begin{tabular}{|c|c|c|c|}
\hline Item & $\mathbf{R}$. & Item & R. \\
\hline \multicolumn{2}{|l|}{ 1. Links } & \multicolumn{2}{|l|}{ 2. Conteúdo } \\
\hline $\begin{array}{l}1.1 \text { O site fornece a localização do usuário em um } \\
\text { conjunto de páginas? }\end{array}$ & Sim & $\begin{array}{l}\text { 2.1 As imagens estão devidamente } \\
\text { etiquetadas? }\end{array}$ & Sim \\
\hline 1.2 As âncoras estão sendo usadas corretamente? & Não & 2.2 As animações em flash estão descritas? & NA \\
\hline 1.3 Há links indicadores na página & Sim & $\begin{array}{l}2.3 \text { A leitura das palavras e frases está sendo } \\
\text { compreendida? Os parágrafos estão com um } \\
\text { tamanho razoável? }\end{array}$ & Sim \\
\hline $\begin{array}{l}\text { 1.4 Os links apresentam descrições curtas e } \\
\text { objetivas? Eles identificam seu destino? }\end{array}$ & Sim & $\begin{array}{l}\text { 2.4 Os arquivos para download apresentam a } \\
\text { extensão a qual são disponibilizados? Eles } \\
\text { estão em formato compatível com o leitor de } \\
\text { telas? }\end{array}$ & Sim \\
\hline $\begin{array}{l}1.5 \text { Os links abrem o conteúdo na mesma página } \\
\text { de navegação ou avisam que irão abrir em uma } \\
\text { nova página? }\end{array}$ & Sim & 2.5 Há verborragia na página? & Não \\
\hline $\begin{array}{l}\text { 1.6 Há atalhos para facilitar a navegação pelo } \\
\text { site? Eles funcionam corretamente? }\end{array}$ & Sim & $\begin{array}{l}\text { 2.6 As tabelas são disponibilizadas apenas } \\
\text { quando necessárias? Seu conteúdo está } \\
\text { mesclado? Há conteúdos que poderiam estar } \\
\text { em tabelas? }\end{array}$ & Sim \\
\hline \multicolumn{2}{|l|}{ 3. Formulários } & \multicolumn{2}{|l|}{ 4. Estrutura do site } \\
\hline $\begin{array}{l}\text { 3.1 Os formulários funcionam corretamente? A } \\
\text { ordem de tabulação está correta? As descrições } \\
\text { dos elementos estão adequadas? }\end{array}$ & Sim & $\begin{array}{l}\text { 4.1 Os menus estão em forma de lista? Quando } \\
\text { há sub-menus ocultos, é disponibilizado um } \\
\text { aviso para mostrar/ocultar esses sub-menus? }\end{array}$ & Sim \\
\hline
\end{tabular}

V. $18 \mathrm{~N}^{\mathrm{o}} 1$, julho, 2020

DOI: 


\begin{tabular}{|l|l|l|l|}
\hline $\begin{array}{l}\text { 3.2 No caso da utilização dos capcha's, há } \\
\text { também uma alternativa em áudio? }\end{array}$ & NA & $\begin{array}{l}4.2 \text { As camadas lógicas estão separadas } \\
\text { adequadamente? }\end{array}$ & Sim \\
\hline $\begin{array}{l}\text { 3.3 As caixas combinadas e de seleção possuem } \\
\text { um botão para o envio ao invés de remeterem } \\
\text { automaticamente quando escolhido um elemento? }\end{array}$ & NA & $\begin{array}{l}4.3 \text { O site possui sumário para conteúdos } \\
\text { longos? }\end{array}$ & NA \\
\hline $\begin{array}{l}\text { 3.4 Há um campo de busca no site? O resultado } \\
\text { da busca é de fácil acesso? }\end{array}$ & Sim & $\begin{array}{l}\text { 4.4 A estrutura das páginas é uniforme? A div } \\
\text { conteúdo encontra-se antes da div menu? }\end{array}$ & Sim \\
\hline $\begin{array}{l}\text { 3.5 Há muitos botões de opções no formulário? } \\
\text { Eles podem ser substituídos por caixa de seleção? }\end{array}$ & NA & $\begin{array}{l}\text { 4.5 Os títulos apresentam uma ordem lógica } \\
\text { no texto? Eles estão descritos corretamente? }\end{array}$ & Sim \\
\cline { 2 - 4 } & & \begin{tabular}{l}
4.6 Existe o Mapa do Site? \\
\cline { 2 - 4 }
\end{tabular} & Sim A tabulação segue a ordem visual da tela? \\
\hline \multicolumn{2}{|c|}{5. Scessibilidade } & Sim \\
\hline 5.1 O site possui a opção de alto contraste? Ela está funcionando corretamente? & Sim \\
\hline 5.2 O site possui uma página com dicas de navegação? & Não \\
\hline 5.3 Há observações extras sobre acessibilidade, usabilidade e comunicabilidade? & Não \\
\hline 5.4 O site possui opções para redimensionamento do texto? &
\end{tabular}

De acordo com a tabela, das 27 respostas, 19 apresentaram conformidade com a regra, 5 não se aplicam ao contexto do website, e somente 3 não apresentaram conformidade, sendo que uma destas referia-se a presença de observações extras (item 5.3), podendo ser considerado como um elemento não obrigatório, mas desejado para melhorias de qualidade. Dessa forma, considera-se que foram encontradas duas violações às regras deste checklist, que dizem respeito à presença de âncoras no website (item 1.2) e à possibilidade de redimensionamento de texto (item 5.4).

$\mathrm{Na}$ avaliação automática, viabilizada pela extensão Visual ARIA, os elementos que possuíam violação à especificação técnica WAI-ARIA foram destacados, apresentando a descrição do problema e como ele deveria ser corrigido. Os resultados desta validação constam na Tabela 2, a partir da qual percebe-se que poucas violações foram encontradas, indicando que, de modo geral, a aplicação foi desenvolvida em conformidade com a especificação técnica WAI-ARIA. As violações encontradas nessas avaliações serão corrigidas na continuidade da implementação da aplicação.

Tabela 2 - Resultados avaliação automática - Visual ARIA

\begin{tabular}{|l|l|l|l|}
\hline Elemento & Local & Violação & Correção \\
\hline MenuItem & $\begin{array}{l}\text { Todas as telas (Menu } \\
\text { de navegação) }\end{array}$ & $\begin{array}{l}\text { Alinhamento } \\
\text { inválido no elemento }\end{array}$ & $\begin{array}{l}\text { O elemento deve ter um elemento pai, com função } \\
\text { de Menu ou MenuBar. }\end{array}$ \\
\hline VideoPlayer & $\begin{array}{l}\text { Telas em que há } \\
\text { vídeos }\end{array}$ & $\begin{array}{l}\text { Elemento sem } \\
\text { etiqueta (label) }\end{array}$ & $\begin{array}{l}\text { O elemento requer um label, para ser devidamente } \\
\text { etiquetado. }\end{array}$ \\
\hline VideoPlayer & $\begin{array}{l}\text { Telas em que há } \\
\text { vídeos }\end{array}$ & $\begin{array}{l}\text { Região de execução } \\
\text { de vídeo sem } \\
\text { atributo "aria-live" }\end{array}$ & $\begin{array}{l}\text { Região de execução de vídeo deve ser } \\
\text { dinamicamente implementada para setar aria-live } \\
\text { com “off” ou "polite", para evitar atualizações } \\
\text { automáticas sem o controle do usuário. }\end{array}$ \\
\hline
\end{tabular}

Ao finalizar o desenvolvimento de todas funcionalidades planejadas, será repetida a avaliação heurística e serão realizadas novas avaliações automáticas de acessibilidade. Além disso, pretende-se realizar avaliações na perspectiva dos requisitos de colaboração e também testes de utilização da aplicação por usuários reais.

\section{Considerações finais}

Este artigo relatou o desenvolvimento de uma rede social de aprendizagem colaborativa para o compartilhamento de materiais didáticos acessíveis a usuários surdos V. $18 \mathrm{~N}^{\circ} 1$, julho, 2020 DOI: 
e deficientes auditivos, que foi implementada seguindo os principais padrões de desenvolvimento web acessível e buscando adequar-se às necessidades dos usuários. Atualmente, a rede social conta com as funcionalidades de gerenciamento de perfil do usuário e de postagens, e na continuação de sua implementação pretende-se incluir as funcionalidades planejadas ainda não implementadas (relacionamentos de amizade, avaliação de usuários e notificações).

No que se refere ao planejamento de novas funcionalidades. entre os trabalhos relacionados, há duas plataformas que podem ser considerados: a DocSity, que oferece um sistema de tira dúvidas dentro da plataforma; e a StudyBlue, que permite a criação de Flash Cards, fichas de estudo, com produção compartilhada entre os usuários. Pretende-se ampliar também os recursos de colaboração da aplicação, acrescentando recursos de comunicação mais eficazes. Para isso, torna-se necessário um novo levantamento bibliográfico, sobre estratégias e ferramentas de colaboração, quesito não aprofundado neste trabalho. A partir disso, serão expandidos os requisitos de colaboração, para que seja possível realizar uma avaliação da aplicação no que tange o atendimento ao Modelo 3C de Colaboração (Fucks e Pimentel, 2011).

Além disso, os dados resultantes das interações com as postagens podem auxiliar na implementação de gamificação na aplicação, a partir da qual pode-se estimular o uso e oferecer recompensas aos usuários que mais compartilham materiais e obtêm mais reações nas suas postagens, como é realizado no Passei Direto. É possível, também, a geração de um sistema de recomendações, para oferecer aos usuários materiais de seu interesse, de acordo com seu objetivo, área de ensino e reações em postagens.

As avaliações realizadas indicam um bom grau de conformidade com os padrões de desenvolvimento web acessível e diretrizes de usabilidade seguidos. No entanto, novas avaliações já estão sendo planejadas, por considerar imprescindível a realização de avaliações em cenários reais de utilização, com acadêmicos surdos, para avaliar tanto a usabilidade quanto a acessibilidade através da análise das experiências dos usuários.

Diante do exposto, considera-se que os principais objetivos deste trabalho foram alcançados, pois a aplicação permite o compartilhamento de materiais didáticos acessíveis, em um ambiente em conformidade com os padrões de acessibilidade e as metas de usabilidade consideradas. Após a finalização do seu desenvolvimento e aplicação de novas avaliações, a rede social será disponibilizada para uso de acadêmicos surdos e deficientes auditivos, com acesso gratuito e ilimitado. Espera-se que, ao utilizar esta rede social, os alunos sintam-se motivados a permanecer em seu curso, ao obter acesso à materiais e conteúdos didáticos que auxiliem no seu processo de ensino-aprendizagem, e consequentemente promovam a sua inclusão educacional.

\section{Referências Bibliográficas}

BARBOSA, G. A. R. Caracterização da Interação Social de Usuários Surdos em Redes Sociais Online: um Estudo de Caso no Orkut. Belo Horizonte: UFMG, 2012, 151p. Dissertação de Mestrado.

BRASIL. eMAG - Modelo de Acessibilidade em Governo Eletrônico 3.0. 2014. Disponível em: <http://emag.governoeletronico.gov.br/>. Acesso em: 39 jun. 2019.

BRASIL. eMAG - Checklist de Acessibilidade Manual para o Desenvolvedor. 2010. Disponível em: <https://www.gov.br/governodigital/pt-br/acessibilidade-digital>. Acesso em: 02 jul. 2019.

FUCKS, H.; PIMENTEL, M. Sistemas Colaborativos. Rio de Janeiro: Elsevier, 2011. 392 p. 
GESSER, A. LIBRAS? Que Língua é essa? Crenças e preconceitos em torno da língua de sinais e da realidade surda. 1. ed. São Paulo: Parábola Editorial, 2009. 87 p.

GIL, A. C. Como elaborar projetos de pesquisa. 6. ed. São Paulo: Editora Atlas, 2018. 169 p. 2. Reimpr.

GOMES, A. P. G.; DALL'ALBA, C.; SARTURI, C. A.; LAZZARIN, M. L. L.; ELSNER, R. M.; HEINZELMANN, R. O. Cadernos Conecta LIBRAS. 1. ed. Rio de Janeiro: Editora Arara Azul, 2015. 90 p.

GONÇALVES, E.; VILELA, J.; PEIXOTO, M.; OLIVEIRA F.; CASTRO, J. Produção de videoaulas de programação em java acessíveis no contexto de um projeto de capacitação profissional para pessoas surdas. In: XXVI SBIE, 26., 2015. Anais.

KITCHENHAM, B.; CHARTERS, S. Guidelines for performing Systematic Literature Reviews in software engineering: Ebse technical report ebse-2007-01. UK: Keele University and Durham University, 2007. 65 p.

LAPOLLI, M.; VANZIN, T.; ULBRICHT, V. R. Infografia na web para a inclusão digital de alunos surdos. RENOTE, Porto Alegre, v. 12, n. 1, 2014.

MEC/INEP. Resumo Técnico Censo da Educação Superior 2017. 2019. Disponível em: <http://portal.inep.gov.br/resumos-tecnicos1>. Acesso em: 10 out. 2019.

MORAIS, R. C. O. Redes Sociais e Aplicativos como Ferramentas de Comunicação dos Surdos. Taubaté: Universidade de Taubaté, 2018, 167p. Dissertação de Mestrado.

NIELSEN, J. 10 Usability Heuristics for User Interface Design. 1994. Disponível em: <https://www.nngroup.com/articles/ten-usability-heuristics/>. Acesso em: 15 ago. 2019.

PREECE, J.; ROGERS, Y.; SHARP, H.; GASPARINI, I.; PIMENTA, M. S. Design de Interação: Além da interação humano-computador. 3. ed. Porto Alegre: Editora Bookman, 2013. 600 p.

QUADROS, R. M.; SOUSA, A. N. de. Tópicos especiais em escrita do português como L2. In: ALMEIDA, N. de; PEIXOTO, J. A. (Ed.). Língua Portuguesa e Libras: teorias e práticas. João Pessoa: Ed. Universitária da UFPB, 2013. v. 7, p. 149-217.

RAMOS, F. M. A Comunidade Surda e o Facebook. Revista Ampliar, Gravataí, v. 1, n. 1, 2014.

SAKIS, I.; BERNARDI, G.; ELSNER, R. Rede Social de Aprendizagem Colaborativa para Surdos e Deficientes Auditivos: uma Avaliação Heurística de Usabilidade e Acessibilidade. In: VI SENID, 6., 2020, Passo Fundo, RS. Anais.

SAKIS, I.; LORENCI, F.; BERNARDI, G. Tecnologias no ensino e aprendizagem de deficientes auditivos: Uma revisão sistemática de literatura. In: XXIX SBIE, 29., 2018, Fortaleza. Anais. Porto Alegre: SBC, 2018, p. 1163-1172.

SARMENTO, C. F.; REGO, H. C. Acessibilidade e inclusão digital de cegos e surdos em plataformas web: um estudo de caso. In: XXVIII SBIE. 28., 2017. Anais.

TAJRA, S. F. Informática na Educação: o uso de tecnologias digitais na aplicação das metodologias ativas. São Paulo: Érica, 2019.

TANAKA, E. H. Método Baseado em Heurísticas para Avaliação de Acessibilidade em Sistemas de Informação. Campinas: Unicamp, 2009, 190p. Tese de Doutorado.

W3C. Accessible Rich Internet Applications (WAI-ARIA) 1.1. 2017. Disponível em: <https://www.w3.org/TR/wai-aria/>. Acesso em: 30 jun. 2019.

W3C. Web Content Accessibility Guidelines (WCAG) 2.1. 2018. Disponível em: <https://www.w3.org/TR/WCAG21/>. Acesso em: 30 jun. 2019. 